\title{
LABORATORY TRIBOLOGICAL TESTS OF METAL-LAYING PLASTIC GREASES
}

\author{
Victor Balabanov ${ }^{1}$, Valery Ostrikov ${ }^{2}$, Sergey Ishchenko ${ }^{3}$
}

${ }^{1}$ Russian Timiryazev State Agrarian University, Russia; ${ }^{2}$ State Scientific Institute All-Russia Research Institute on Use of Technics and Mineral Oil of Russian Academy of Agricultural Sciences, Russia;

${ }^{3}$ Primorsky State Agricultural Academy, Russia

vbalabanov@rgau-msha.ru, viitinlab8@bk.ru,dir_nikolsk@mail.ru

\begin{abstract}
The literature-patent analysis shows that the use of metal-clad plastic lubricants in transmission elements, the chassis of automotive vehicles and parts of various equipment is quite effective in order to increase the scoring resistance, wear resistance and partial restoration of microdefects of rubbing surfaces. The paper presents the results of laboratory tribological testing of well-known metal-clad plastic lubricants. The tests were carried out on a Timken-Mashine friction machine according to the "ring-roller" scheme with friction of the upper roller specimen along the lower ring specimen made of ШX-15 ball-bearing steel. Test modes: specific pressure in the contact zone $p=10 \mathrm{MPa}$, sliding speed $v=1.83 \mathrm{~m} \cdot \mathrm{s}^{-1}$, lubricant was supplied to the friction zone by spreading, the time of one test was $t=3600 \mathrm{~s}$. The study of the chemical composition of the coating and the transition zone of the friction surface formed during friction in the presence of metal-clad lubricant was performed using a Cambridge Instrument Stereoscan-360 scanning microscope. For comparison, the results of the tests of the same structural materials with Litol 24 grease without additives were taken. It has been established that the use of metal-clad plastic greases can reduce the wear of prototypes in comparison with the base Litol 24 grease on average from $3.5 \mathrm{mg}$ to $1.5-0.2 \mathrm{mg}$ (from 2.1 to 16 times), and the use of a metal clad developed by the authors Metal Plus grease provides restoration of the weight of samples by an average of 0.1 $\mathrm{mg}$ due to the formation on the friction surfaces of a composite copper-tin-nickel coating with a thickness of about $1.0 \mu \mathrm{m}$, as well as a diffusion zone with a depth of up to $12.5 \mu \mathrm{m}$, due to what increased wear resistance of samples is achieved and partial restoration of worn friction surfaces.
\end{abstract}

Keywords: metal-clad plastic lubricant, friction machine, laboratory tribological tests, sample wear, restoration of friction surfaces.

\section{Introduction}

The world's leading petrochemical concerns produce plastic lubricants, which are also intended for restoration of friction surfaces of parts. So, the company Actex S.A. (France) manufactures Lubri Grease metal-clad plastic grease containing a lithium base and a lead-silver-copper alloy. NV company Marly. SA (Belgium) manufactures Copper Compound copper-based grease. Permatex Inc (USA) manufactures Nickel Anti-Seize Lubricant metal-clad plastic grease with nickel microparticles designed to operate at high temperatures up to $\left(+1300^{\circ} \mathrm{C}\right)$. From domestic developments, it is necessary to indicate the multipurpose metal-clad lubricant "SHRUS MS" from the LLC "VMPavto".

Analysis of literature and patents suggests that the use of metal-clad plastic lubricants in transmission elements and the chassis of automotive vehicles and parts of various equipment is quite effective in order to increase the scoring resistance, wear resistance and partial restoration of microdefects of rubbing surfaces [1-5].

The article presents some results of laboratory tribotechnical testing of the most famous metalclad lubricating greases (table) and developed by the authors the new metal-clad lubricant "Metal Plus" containing compounds of ductile metals: copper, tin and nickel [5].

The purpose of the research was to evaluate the effectiveness of using various metal-coating lubricants to reduce the wear of rubbing samples.

\section{Materials and methods}

For the research, the most well-known and commercially available metal-coating lubricants were taken and the new composition "metal plus" developed by the authors, containing compounds of polyvalent metals: copper, tin and nickel [5].

As a comparison base, the test results of the same structural materials with Litol 24 grease without the use of any additives were taken. 
Name, manufacturers and regulatory documents, tested metal plating greases

\begin{tabular}{|l|c|c|}
\hline \multicolumn{1}{|c|}{ Name } & Manufacturers & Regulatory documents \\
\hline 1. Litol 24 & LLC "Expert Oil" & Standard 21150-87 \\
\hline 2. AVTO grease & STC "RemAvto" & TS 02-58178995-3-92 \\
\hline 3. Metapol & NPF "Ellis" & TS 1-92-193-95 \\
\hline 4. SHRUS MS & LLC "VMPAVTO" & TS 0254-011-45540231-2004 \\
\hline 5. Vympel & NPF "Fine metal powders Co" & TS 0254-026-12288799-2005 \\
\hline 6. Metal Plus & RSAU-MTAA & TS 4366.03.03049297-2011 \\
\hline
\end{tabular}

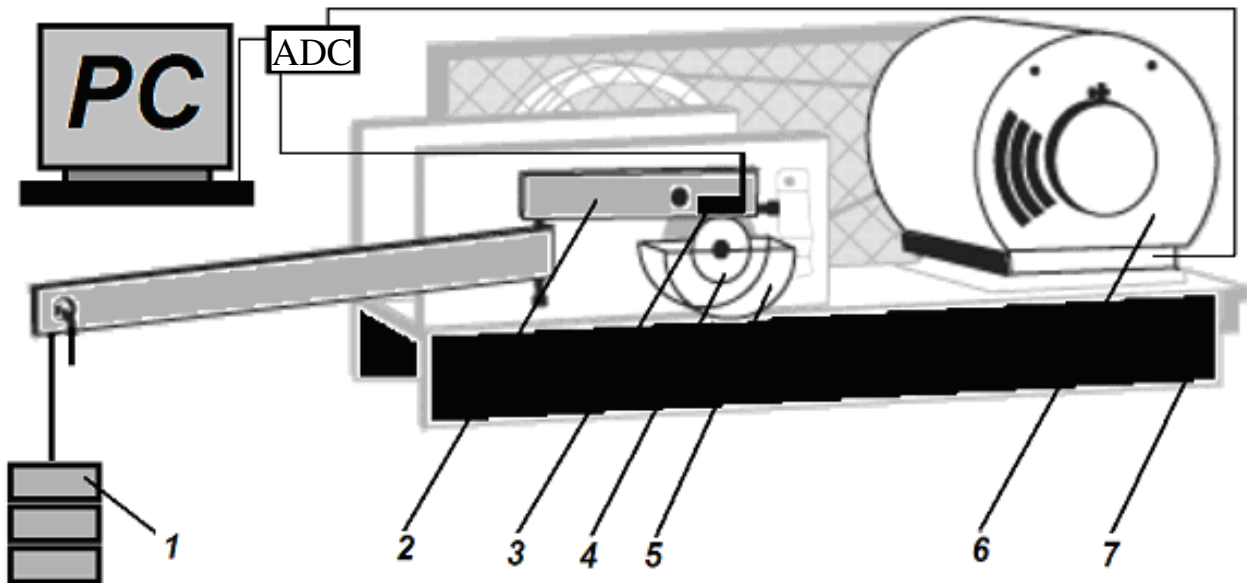

Fig. 1. Scheme of the modernized Timken-Mashine friction machine: 1 - cargo; 2 - load mechanism; 3 - upper roller sample with a temperature sensor; 4 - lower annular sample; 5 - cuvette for lubricant; 6 - electric motor; 7 - bed; ADC - analog-to-digital converter; $\mathrm{PC}$ - personal computer with software

The comparative tribotechnical tests were carried out at the Russian State Agrarian University Moscow Timiryazev Agricultural Academy on a modernized Timken-Mashine friction machine. The scheme of the modernized Timken-Mashine friction machine is shown in Figure 1, and a general view in Figure 2.

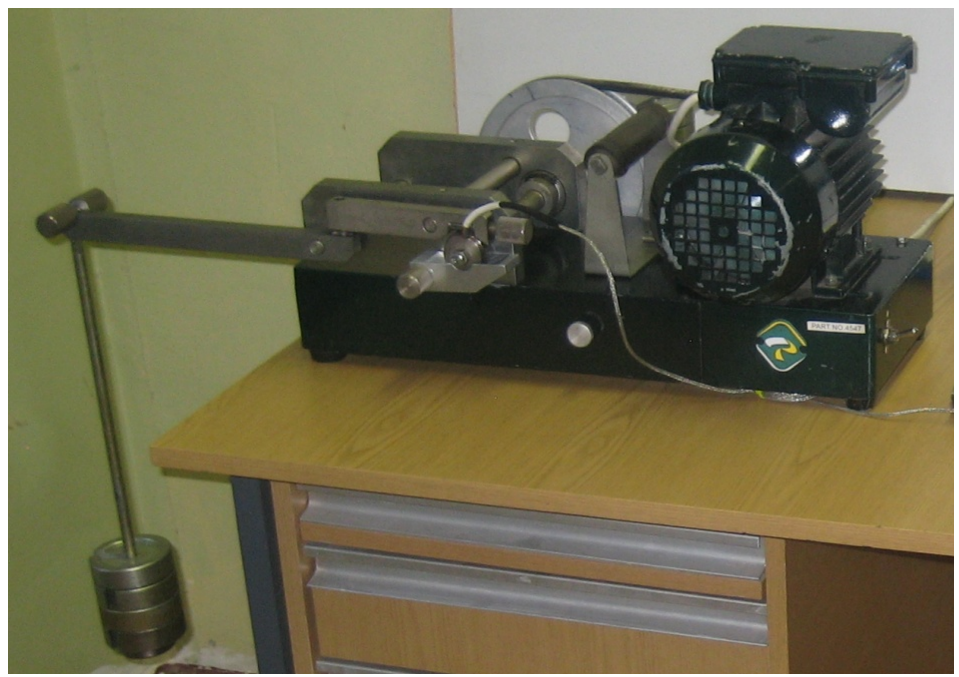

Fig. 2. General view of the modernized Timken-Machine friction machine

The principle of operation of the Timken-Mashine installation is based on performing rotational motion according to the "ring-roller" scheme with friction of the upper roller sample 3 along the lower ring sample 4 (Fig. 3-4). 
The comparative laboratory tribotechnical tests of various greases were carried out in the steady state using real rolling bearing assemblies: an inner cage and rollers with a diameter of $8 \mathrm{~mm}$ of a rolling bearing type 7202 made of steel ШX-15.

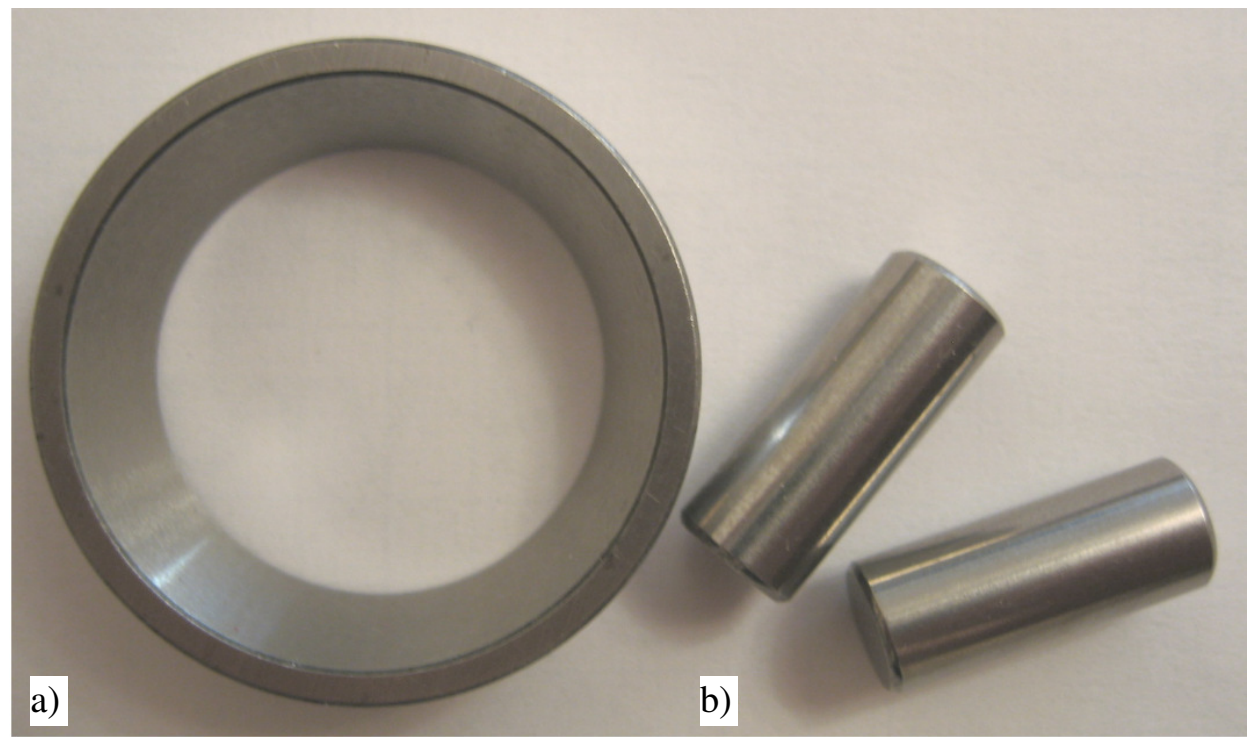

Fig. 3. General view of the samples for tribological testing on a Timken-Mashine friction machine: $\mathrm{a}$ - lower annular, $\mathrm{b}$ - upper roller

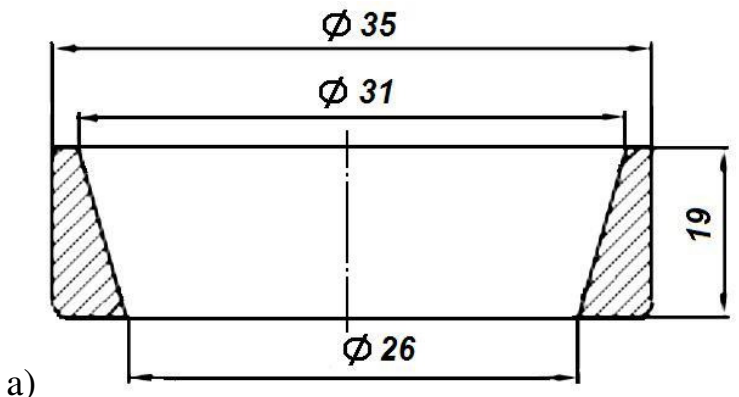

b)

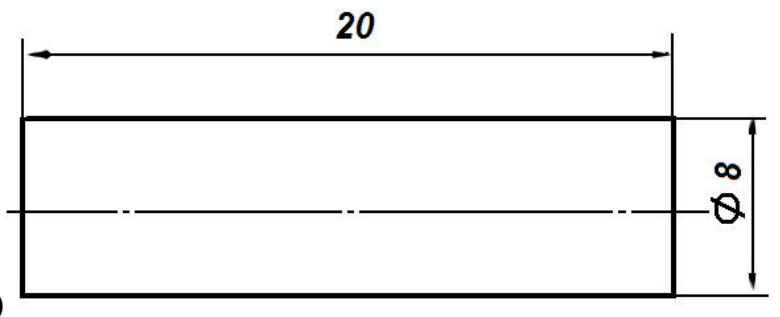

Fig. 4. Sketches of samples for the Timken-Mashine friction machine:

$\mathrm{a}$ - lower annular, $\mathrm{b}$ - upper roller

The laboratory tribotechnical tests were determined by the structural capabilities of the friction machine: specific pressure in the contact zone $p=10 \mathrm{MPa}$, sliding speed $v=1.83 \mathrm{~m} \cdot \mathrm{s}^{-1}$, lubricant was supplied to the friction zone by spreading, the time of one test was $t=3600 \mathrm{~s}$.

The repeatability of experiments on each test was equal to five, while the error of experiments was no more than $5 \%$.

The wear recovery of the test samples was determined at the end of each test by the weighing method on a WA-21 analytical balance (Mechaniki zaklady precyzyjnej, Poland) with a weighing accuracy of up to $0.0001 \mathrm{~g}$. For study of the chemical composition of the coating formed during friction and the transition zone of the rubbing surface a scanning microscope was used of the Stereoscan-360 brand from Cambridge Instrument, which makes it possible to analyze the chemical composition at given points $[2-3 ; 5]$.

\section{Results and discussion}

As the result of laboratory tribotechnical tests, it was found that the use of metal-clad lubricants provides reduced wear of samples compared to Litol 24 base grease on average from $3.5 \mathrm{mg}$ to 1.5 $0.2 \mathrm{mg}$, which is from 2.1 to 16 times. When testing prototypes with the developed Metal Plus metalclad lubricant, an increase in the weight of the test samples by an average of $0.1 \mathrm{mg}$ was noted (Fig. 5). 


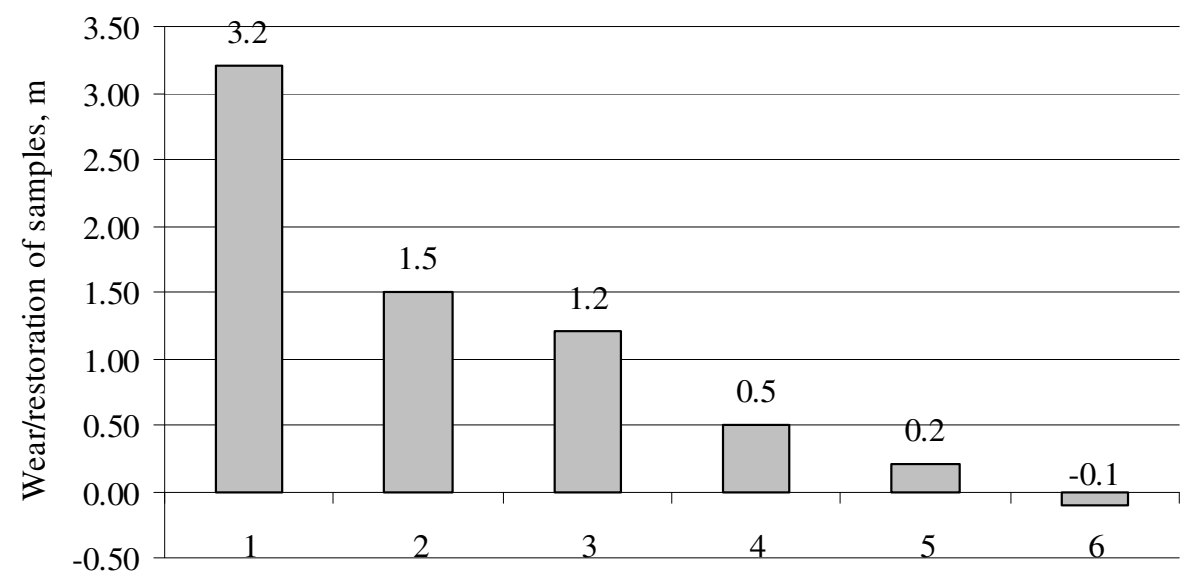

Fig. 5. Wear/restoration of rubbing samples (mg) after tribological testing: 1- Litol 24;

2 - AVTO grease; 3 - SHRUS MS; 4 - Metapol; 5 - Vympel; 6 - Metal Plus

As we can see, the developed Metal Plus lubricant can be used not only to reduce the wear of friction joints, but also as a reducing lubricant for partial restoration of friction surfaces, such as rolling bearings and possibly some other parts.

As the result of physicochemical studies and analysis of the friction surfaces of the samples, it was found that the Metal Plus metal-clad plastic grease forms a composite copper-tin-nickel coating on the contact surfaces, with a thickness of up to $1.0 \mu \mathrm{m}$, as well as a diffusion zone with a thickness of up to $12.5 \mu \mathrm{m}$ that provides partial restoration of microdefects of the friction surfaces and increases the wear resistance of lubricated friction surfaces (Fig. 6) [4-5].

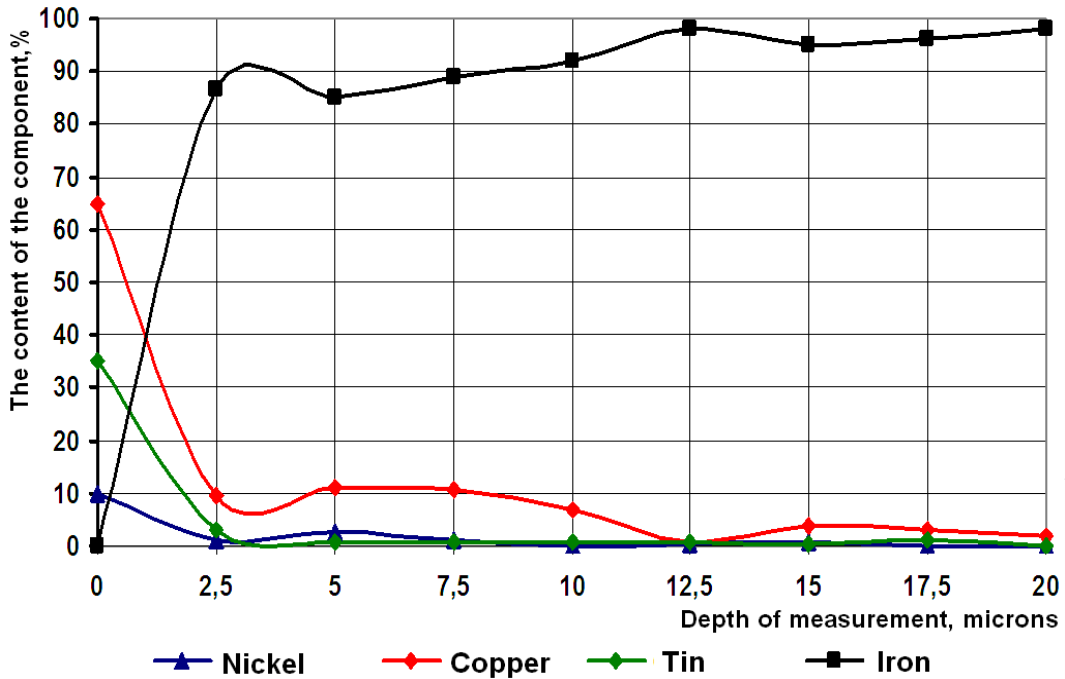

Fig. 6. Component composition of the friction surfaces of the samples after the use of metal-plating grease "Metal Plus"

The research results suggest that, when friction occurs on the contact surfaces, metal plating processes are described in detail in the works on the "no-wear effect", which results in formation of protective coatings made of polyvalent (plastic) metals with high anti-wear properties [6-8].

The process of cladding friction compounds with plastic metals is carried out by chemical reduction and deposition of plastic metals from salts in the presence of surfactants and physical rubbing of ultrafine powders contained in the lubricant composition with the developed additive. The friction surfaces are covered with a composite protective film made of plastic metals, which partially restores the size and tribological characteristics of the contacting surfaces [6-8].

\section{Conclusions}

1. The use of metal-clad lubricants can reduce the wear of prototypes in comparison with the base lubricant Litol 24 on average from $3.5 \mathrm{mg}$ to $1.5-0.2 \mathrm{mg}$ (from 2.1 to 16 times). 
2. As the result of tribotechnical testing of samples using the developed metal-plating grease brand Metal Plus, an increase in the weight of the studied samples by an average of $0.1 \mathrm{mg}$ was recorded.

3. Physico-chemical studies of rubbing samples show that the Metal Plus metal-clad lubricating grease forms a composite copper-tin-nickel coating on the friction surfaces with a thickness of up to $1.0 \mu \mathrm{m}$ and a diffusion zone up to $12.5 \mu \mathrm{m}$ deep, which ensures increasing their wear resistance and partial restoration of microdefects of rubbing surfaces.

4. Based on the conducted tribotechnical studies, it can be assumed that the metal-coating lubricant Metal Plus can be used not only to reduce wear, but also to partially restore friction joints, for example, rolling bearings.

\section{References}

[1] Potapov G.K. The method of continuous recovery of rubbing joints/RF Patent 2062821. Bull. No. 18, 1996. - 4 p. (In Russian).

[2] Balabanov V.I. Improving the quality of repaired internal combustion engines by implementing selective transfer during friction // Vestnik mashinostroeniya, 2001. No. 8. pp. 14-19. (In Russian).

[3] Beklemyshev V.I., Makhonin I.I., Lepgov A.F. and others. The influence of organometallic additives RENOM on the friction surface and indicators of automotive technology // Herald of mechanical engineering. 2004. No. 10. pp. 51-55. (In Russian).

[4] Patent 2432386. Metal-clad reducing additive to plastic lubricants. V.V. Lehter. and others. Bull. No. 30. dated October 27. 2011, application No. 2009145822 dated 12/12/2009 (In Russian).

[5] Lehter V.V. Restoring the health of rolling bearings of agricultural machinery movers with metalclad plastic grease: author. dis. ... cand. those. sciences./Lekhter Valentina Vladimirovna, Moscow, MGAU, 2010. 16 p. (In Russian).

[6] Garkunow D.N. Einige Erkentnise zu der Prozessen bei der selektiven Übertragung // Schmierungstechnik. Fachzeitsschrift fur Tribotechnik. Verlag Technik Gmb H, Berlin, 1990, H.12.- pp. 361-362.

[7] Marczak R., Stand und notwendige Entwicklungsrichtungen bein Effekt der selektiven Übertragung (Status and necessary development directions based on the effect of selective transmission), Smierungstechnik, Berlin 21. (1990). H. 12.- pp. 366-367. (In German)

[8] Polzer G. und an. Reibbeschichten und selektiven Übertragung (Friction coating and selective transmission), Zwikkau, 1988. 88 p. (In German) 